\title{
Hyperventilation and seizures in an adolescent female
}

\author{
F. Nicosia1, L. Giordano2, L. Bonini2, L. Corda3 ${ }^{3}$ M. Bolzon4, \\ M. Bettinzoli5, A. Braghini5, P. Accorsi², C. Tantucci5
}

\begin{abstract}
Hyperventilation and seizures in an adolescent female. F. Nicosia, L. Giordano, L. Bonini, L. Corda, M. Bolzon, M. Bettinzoli, A. Braghini, P. Accorsi, C. Tantucci.

A 16 year-old girl was admitted after suffering from recurrent episodes of dyspnea and stridor, cyanosis, loss of contact, stiffening of all four limbs, clenching of the jaw and eye retroversion that lasted for a few seconds to a minute, followed by slow recovery of consciousness without any loss of sphincter control. These symptoms began at the age of 11 and worsened over time. Prolonged rate corrected QT intervals was observed with an ECG. Two cardio-respiratory monitorings were performed (one during daytime hours while the patient was awake, and one at night time while the patient slept). Daytime recordings showed 17 central apnoeas and 97 central hypopneas, with an apnea-hypopnea index (AHI) of 13.2 events/hour, that were associated with severe oxyhemoglobin desaturation. In contrast, night time recordings were
\end{abstract}

normal (AHI=1.1 events/hour). The patient underwent diurnal monitoring of transcutaneous $\mathrm{pCO}_{2}\left(\mathrm{PtcCO}_{2}\right)$, transcutaneous $\mathrm{O}_{2}\left(\mathrm{PtcO}_{2}\right), \mathrm{SpO}_{2}$ and end tidal $\mathrm{CO}_{2}$ $\left(\mathrm{P}_{\mathrm{ET}} \mathrm{CO}_{2}\right)$, with simultaneous monitoring of regional cerebral oxymetry $\left(\mathrm{rSO}_{2}\right)$ which showed values of $\mathrm{PtcCO}_{2}$ between 8 and $15 \mathrm{mmHg}$, suggesting several episodes of marked hyperventilation. Twenty-nine episodes of severe arterial desaturation $\left(\mathrm{SpO}_{2}<\mathbf{5 0 \%}\right)$ were registered, all after the same number of apnea events, with ascent of $\mathrm{PtcO}_{2}$ up to $28 \mathrm{mmHg}$ at the end of apnea. During the final phase of apnea, the patient showed cyanosis, contact disturbance, grimaces, oral movements of rhyme, and, on three occasions, partial seizures. A mask was packaged and applied daytime to the face of the patient during episodes of hyperventilation to prevent, together with a psychiatric follow up, rapid falls of $\mathrm{PaCO}_{2}$ levels determining central apnoeas.

Monaldi Arch Chest Dis 2013; 79: 2, 93-95.

Keywords: Apnea, Psychiatric disorder, Hypocapnia.

1 Cattedra di Geriatria, Università di Brescia;

2 Servizio di Neuropsichiatria Infantile, Ospedale dei Bambini, Brescia;

3 Prima Medicina Interna, Spedali Civili, Brescia;

4 Servizio di Neuroanestesia e Neurorianimazione, Ospedale Niguarda Cà Granda, Milano;

5 Cattedra di Malattie dell' Apparato Respiratorio, Università di Brescia, Italy.

Correspondence: L. Corda, Prima Divisione di Medicina Interna, Spedali Civili, Piazzale Spedali Civili 1, 25123 Brescia, Italy; e-mail: luciano.corda@spedalicivili.brescia.it

\section{Case Report}

H.A., female, of Moroccan origin, aged 16, was admitted to the Child Neuropsychiatry Unit of our hospital because she was affected by recurrent episodes of dyspnea and stridor, associated to cyanosis, loss of contact with stiffening of all four limbs, clenching of the jaw and eye retroversion which lasted for a few seconds to one minute, followed by slow recovery of consciousness without any loss of sphincter control.

The mother of the patient referred that these symptoms began at the age of 11 , worsened over time, resulted associated with ideomotor response slowdown, and led to the gradual withdrawal and loss of autonomy.

Upon admission to our hospital, the patient's neurological, cardiopulmonary examinations, standard blood tests, chest X-ray and pulmonary functions were normal although she had a body mass index (BMI) of 14.6 and a significant reduction in muscle mass.
Subsequently, the patient was referred to the Cardiovascular Unit to exclude heart disease. An echocardiogram was normal while a 24hour ECGHolter (2 recordings) showed values of QT (corrected according to the Bazet's formula) consistently high, up $510 \mathrm{msec}$, which were confirmed by a 12-lead surface ECG. In order to relate the clinical findings and the alterations of QTc, Rett syndrome was suspected. However, search for the MECP2 Rett Syndrome related gene and for the long QT syndrome gene resulted negative.

The patient did not perform a cardiopulmonary exercise test as she was unable to carry out a minimum exercise load, due to the lack of physical strength.

During wakefulness Electroencephalography (EEG) recordings, a widespread slowdown in cerebral electric activity was observed, with an onset of crisis arising from the right temporal lobe at the end of apnea. A brain Magnetic Resonance Imaging (MRI) and Computed Tomography (CT) at rest were normal and Ear, Nose and Throat (ENT) evaluation showed normal findings. 
Sodium valproate, carbamazepine, diazepam, amitriptyline, lorazepam, theophylline were introduced, at different doses and in different associations with no clinical benefits. The patient was followed-up for six months and the clinical picture progressively worsened with increased numbers of the above mentioned episodes along with progressive physical deterioration.

After the second admission, some tests were repeated (Holter ECG, EEG), confirming the previous findings.

The cognitive level was normal for her age (the patient has learned the Italian language in 3-5 months). During wakefulness, some episodes of hyperventilation followed by central apnoeas were observed by the clinicians. Two cardio-respiratory monitorings were performed: one during daytime hours while the patient was awake, and one during the night while the patient slept, registering nasal flow (pressure transducer and thermistor) and oral (thermistor), thoracic-abdominal movements (piezo bands), oxyhemoglobin saturation $\left(\mathrm{SpO}_{2}\right)$, heart rate, ECG, snoring and body position (polygraph Siesta 802, Compumedics Ltd, Abotsford, Australia). During diurnal recordings, the patient, while awake, had 17 central apnoeas and 97 central hypopneas, with an apnea-hypopnea index (AHI) of 13.2 event/hour. Mean oxyhemoglobin saturation was $87 \%$ with periods $<90 \%$ of 2 hours and 38 minutes, $<85 \%$ of 2 hours and 18 minutes, and $<80 \%$ of 2 hours and 3 minutes. During night recordings these findings were not present with AHI of 1.1 event/hour.

The patient underwent diurnal monitoring (6 hours and 15 minutes) of transcutaneous $\mathrm{pCO}_{2}$ $\left(\mathrm{PtcCO}_{2}\right)$, transcutaneous $\mathrm{pO}_{2}\left(\mathrm{PtcO}_{2}\right), \mathrm{SpO}_{2}$, and end tidal $\mathrm{CO}_{2}\left(\mathrm{P}_{\mathrm{ET}} \mathrm{CO}_{2}\right)$ and simultaneous moni- toring of regional cerebral oxymetry $\left(\mathrm{rSO}_{2}\right)$ with a near infrared spectroscopic method (Near Infrared Spectroscopy, NIRS) during the last 2 to 6 hours. During monitoring, the patient had almost constant hyperventilation with values of $\mathrm{PtcCO}_{2}$ between 8 and $15 \mathrm{mmHg}$ (figure 1), confirmed by arterial blood gas analysis (ABG), and severe respiratory alkalosis ( $\mathrm{pH}$ 7.64-7.69). The values of $\mathrm{P}_{\mathrm{ET}} \mathrm{CO}_{2}$ showed a similar trend. Normal values of $\mathrm{SpO}_{2}$ or high values of $\mathrm{PtcO}_{2}$ were recorded during hyperventilation. Twenty-nine episodes of severe arterial desaturation $\left(\mathrm{SpO}_{2}<50 \%\right)$ were recorded, all after the same number of apnea episodes lasting about 60-120 seconds, with an ascent of $\mathrm{PtcCO}_{2}$ up to $28 \mathrm{mmHg}$ at the end of apnea. In the final phase of apnea, the patient always showed signs of cyanosis, contact disturbance, grimaces, oral movements of rhyme, and, on three occasions, partial seizures. At the end of the longest recorded periods of apnea, ventilation resumed with a groan as inspiratory stridor. During 116 minutes of monitoring, 13 episodes of $\mathrm{rSO}_{2}$ fall were observed, with a decrease of more than $20 \%$ from the baseline, and in 7 out of 13 cases more than 25\% from the baseline. Hyperventilation was characterized by high values of tidal volumes and relatively low frequency.

A mask was packaged and applied to the face of the patient during hyperventilation to prevent marked falls of $\mathrm{PaCO}_{2}$ levels in order to avoid functional central apnea. The patient accepted its application by female medical staff only, and, after some practice, she was well and conducts an acceptable social life thanks to a psychiatric follow up. The clinical pattern may be included in the "hysterical spectrum" of DSM-IV, possibly due to histrionic traits, eating and somatoform disorders.

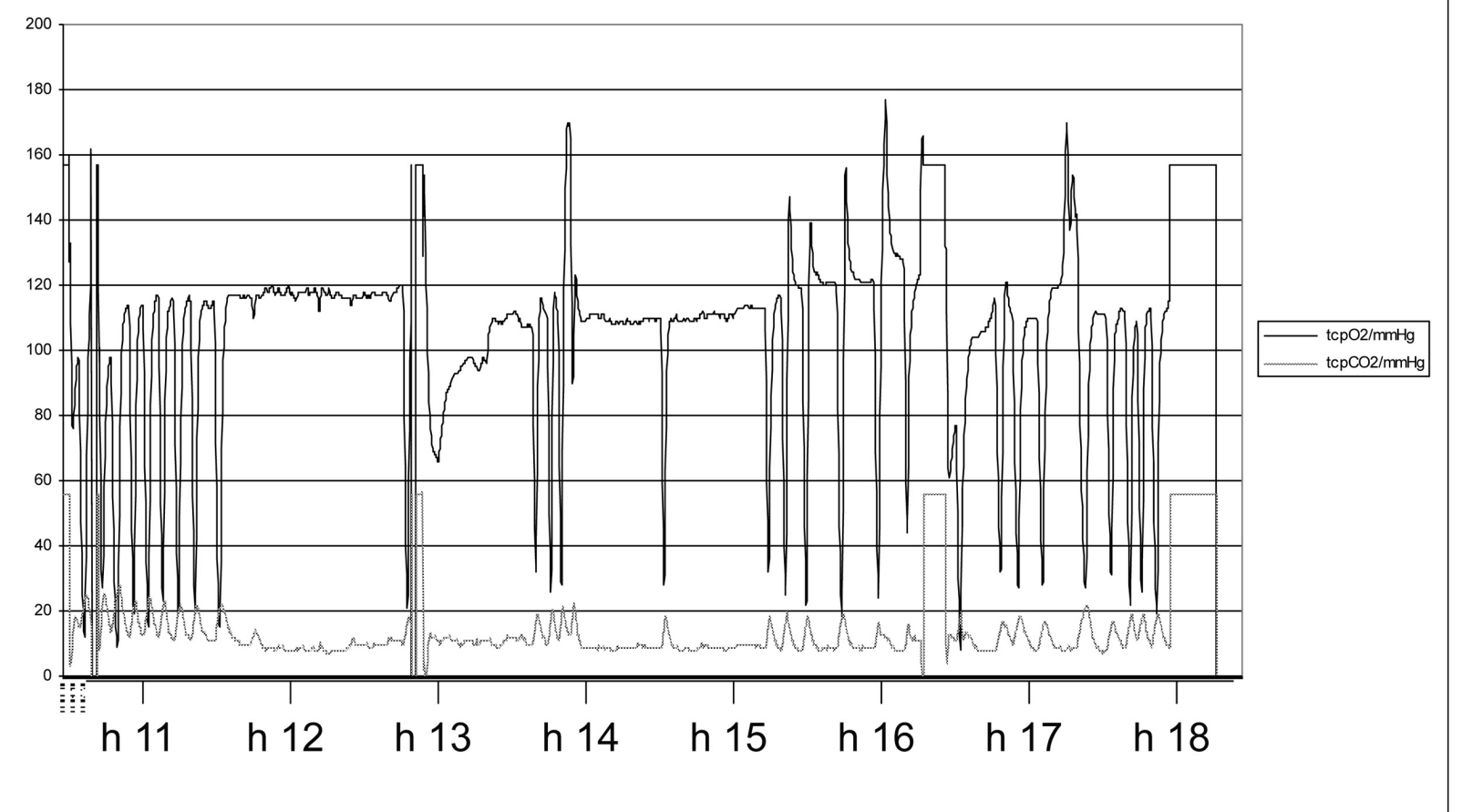

Fig. 1. - Seven hour recording of awake transcutaneous $\mathrm{CO}_{2}\left(\mathrm{PtcCO}_{2}\right)$ and transcutaneous $\mathrm{O}_{2}(\mathrm{PtcO})(\mathrm{X}$ axis: time, $\mathrm{Y}$ axis: mmHg). 


\section{Discussion}

We describe the case of a teenager who had repeated episodes of hyperventilation due to psychiatric disorders leading to extremely low levels of $\mathrm{PaCO}_{2}$ capable of inducing central apnoeas during wakefulness.

The ensuing severe hypoxemia was believed to be responsible for subsequent occurrence of seizures through a reflex cerebral anoxia mechanism. It is very rare to reach the inspiratory threshold of $\mathrm{PaCO}_{2}$ while awake with consequent functional central apnea. This requires a highly performing gas exchange apparatus capable of rapidly eliminating large amounts of $\mathrm{CO}_{2}$, associated with low functional residual capacity (poor dumping effect) and chronically low bone deposits of $\mathrm{CO}_{2}$ as was likely the case with this girl.

We report such events in a young woman, admitted with severe neurologic disturbances, suffering from psychiatric disorder.

Pseudoresistance, in which seizures persist because epilepsy has not been correctly diagnosed or appropriately treated, must be excluded before drug treatment can be judged as ineffective. This phenomenon may arise in a number of situations, in which misdiagnosis of epilepsy is probably the most common (for instance: vasovagal syncope, cardiac arrhythmias, metabolic disturbances, transient ischemic attacks and migraine); psychogenic, nonepileptic seizures, are estimated to account for more than $25 \%$ of all adult cases of apparently drug-resistant epilepsy [7]. A complete diagnosis of epilepsy requires differentiation of seizures from other causes of altered consciousness behaviour, differentiation of spontaneous unprovoked seizures (epilepsy) from provoked seizures (e.g. reflex anoxia) [8].

We excluded Rett syndrome, a severe neurodevelopment disorder in which children show a marked neurological decline with a highly variable course which can include an early period of developmental regression followed by phases of symptoms stabilization as well as late deterioration. Initial manifestations of the disease may include loss of acquired speech, head growth deceleration and autistic features such as emotional withdrawal and diminished eye contact. Subsequently, such patients develop motor stereotypes, epileptiform seizures, exaggerated responses to stress and autonomic dysfunction. Of particular relevance is that the majority of Rett syndrome patients also develop severe breathing abnormalities. Prolonged, rate corrected QT intervals (QTc) have also been identified in patients with Rett syndrome [9].

In the patients studied, the long QT may be affected by the ion displacement secondary to hyperventilation and alkalosis; however, we have in- formation to suggest that QT did not change after two months from treatment institution. In addition, stridor and groaning do not suggest a collapse of upper airways, but a vocal cord closure. This phenomenon has been reproduced in normal subjects with experimental hypocapnia [10] and is probably the case in this girl also. Conversely, considering the pseudo-tetanic stiffening of all muscles, laringeal muscles could instead be primarily affected and not be the result of a sort of protective reflex trying to treasure the small reserves of alveolar $\mathrm{CO}_{2}$.

Respiratory symptoms, more or less complex, may be an epiphenomenon of respiratory, cardiovascular, but sometimes also of psychiatric or neurological diseases. Distinguishing among these diseases is not always easy and can lead to several useless diagnostic tests.

Economic conditions, the certainty that the nature of the disorder was functional, the impossibility of taking full charge of the patient has led to package a special face mask that, when applied to the patient during hyperventilation episodes, was effective in preventing related acute symptoms. This solution improved the physical condition of the patient, her familiar and social relationships, and allowed her to discontinue taking anti-epileptic drugs.

\section{References}

1. Marcus CL, Carrol JL, McColley SA, et al. Polysomnographic characteristics of patients with Rett Syndrome. J Pediatr 1994; 125: 218-224.

2. Katz DM, Dutschmann M, Ramirez JM, Hilaire G. Breathing disorders in Rett syndrome: progressive neurochemical dysfunction in the respiratory network after birth. Respir Physiol Neurobiol 2009; 168: 101-108.

3. Ellaway CJ, Sholler G, Leonard H, Christodoulou J. Prolonged QT interval in Rett syndrome. Arch Dis Child 1999; 80: 470-472.

4. Eberhard P. The design, use and results of transcutaneous carbon dioxide analysis: current and future directions. Anesth Analg 2007; 105: S48-S52.

5. Wieling W, Thijs RD, van Dijk N, Wilde AA, Benditt, van Dijk JG. Symptoms and signs of syncope: a review of the link between physiology and clinical clues. Brain 2009; 132: 2630-2642.

6. Bhatia MS. Pseudoseizures. Indian Pediatr 2004; 41: 673-679.

7. Kwan P, Schachter SC, Brodie MJ. Drug-Resistant Epilepsy. N Engl J Med 2011; 365: 919-926

8. Smith D, Defalla BA, Chadwick DW. The misdiagnosis of epilepsy and the management of refractory epilepsy in a specialist clinic. QJM 1999; 92: 15-23.

9. Ellaway CJ, Sholler G, Leonard H, Christodoulou J. Prolonged QT interval in Rett syndrome. Arch Dis Child 1999; 80: 470-472.

10. Jounieaux V, Aubert G, Dury M, Delguste P, Rodenstein DO. Effects of nasal positive-pressure hyperventilation on the glottis in normal awake subjects. $J$ Appl Physiol 1995; 79: 176-85. 